\title{
KEY FACTORS HINDERING SUSTAINABLE PROCUREMENT IN THE BRAZILIAN PUBLIC SECTOR: A DELPHI STUDY
}

\author{
BRUNO B.F. DA COSTA \& ANA LÚCIA T.S. DA MOTTA \\ Department of Civil Engineering, Fluminense Federal University, Brazil.
}

\begin{abstract}
The modern lifestyle has resulted in a gradual dismantling of the vital services offered by nature, putting human existence at risk. In this sense, it is understood as a Public Administration responsibility the active participation in the promotion of sustainable consumption and production strategies, not only through public policies implementation, but also through its abundant purchasing power. Thus, the present investigation aims to identify and classify the main barriers that have hampered the massive application of sustainable public procurement (SPP) in Brazil. The proposed objective was achieved through a Delphi study. A panel of experts identified 32 main obstacles for SPP implementation, which were subsequently ranked according to a five-point Likert scale. The results suggest that, among all the barriers identified, 10 are the leading factors that hinder the implementation of SPPs in the Brazilian public sector. The findings of this paper, therefore, provide a valuable reference for experts and practitioners in the selection of the obstacles that must be firstly overcome to stimulate the application of SPPs. Keywords: Barriers, Brazil, Delphi study, public sector, sustainable consumption, sustainable production, sustainable public procurement.
\end{abstract}

\section{INTRODUCTION}

Public procurement (PP) refers to the purchase of goods and services by governments or public institutions through a public contract [1]-[4]. In other words, 'is concerned with how public sector organisations spend taxpayers money' [5] to perform their functions and deliver its services [6]. According to [7], 'the public procurement market is considered to be the largest business sector in the world', being reputable as a key economic activity of governments [8]. It represents, approximately, $16 \%$ of the gross domestic product (GDP) of the European Union (EU) [7]-[11], and between $8 \%$ and $25 \%$ of the GDP in organization for economic cooperation and development (OECD) countries [5],[8]-[10], granting the public sector a high purchasing power [11].

In light of the aforementioned scale of this market, procurement is currently perceived as an important policy instrument [2],[8],[12],[13], presenting a significant potential to shape production and consumption trends [11], driving countries to the creation of a more sustainable economy. In practice, governments can use PP as a lever to achieve broader policy goals [8]. This means that public purchases should not be recognized as simple acquisition processes anymore, but as strategic tools for the effective conversion of socio-environmental policies into sustainable acquirements [14]. Hence, there is a need for the state to play a more active role in environmental protection [15], in addition to establish wider objectives in their purchases, such as societal well-being and economic development [16]. Therefore, governments 'not only ask citizens to be environmentally conscious' [17], but sets an example by means of a socio-eco-friendly buying process, which is called sustainable public procurement (SPP) [9].

In spite of the several benefits inherent in this new concept of procurement [16], the theme 'has only relatively recently been the subject of considerable academic research' [8]. To date 
extant literature indicates a limited exploration in the context of the public sector [9],[13],[18], with the great majority of these studies being carried out in private companies [19]-[22]. Furthermore, there is a preponderance of works conducted in developed countries such as Sweden [23], UK [16],[24-26], Spain [3],[27], The Netherlands [7],[28], USA [18],[29], Australia [30], Norway [1], Denmark [31], Germany [32] and Canada [33], while SPP surveys within the context of developing and underdeveloped countries have been systematically neglected [34]. Whereas achieving a sustainable level of consumption and production 'requires a diversified approach in developed and developing economies' [35] since their intrinsic characteristics vary in relation to their consumption patterns, economic condition, industrialization level, demography and socio-cultural factors [34],[36], this research fills this gap through a study in Brazil, a developing country and the largest economy in Latin America.

Government purchases from Brazil comprise about 10-15\% of the country's GDP each year, representing a billion dollar market [37],[38]. However, there is a critical lack of SPP studies in the Brazilian context [38], whose field of knowledge has been considered less structured than in other nations [39]. Due to this shortage, procurers have been hesitant to adopt sustainable practices since there is no well-defined selection criteria that allows the option for the best value alternative instead of the lowest bid [33]. Although many surveys have indeed pointed out cost as the primary component and strongest barrier in performing SPP [2],[34],[40], there are other numerous obstacles influencing its implementation, such as lack of funding [24],[28], inadequate market supply of sustainable services and products [41], low social and environmental awareness [42], insufficient policies and regulation [33], as well as deficient training and education of purchasers and suppliers [21].

The objective of this paper is to identify and classify the main barriers that have hampered the massive application of SPPs in Brazil. Considering the limited quantitative studies available, this ranking approach becomes extremely relevant in order to highlight the most feared obstacles and the necessary steps to be taken to prevent or solve them, since literature is dominated by suggestions of various scholars that lack empirical evidences to be proven [43].

The proposed objective was achieved through a Delphi study. A panel of renowned experts was assembled and after three rounds, 32 barriers to the implementation of sustainable procurements in Brazil were identified and classified according to a five-point Likert scale. Secondly, a literature review was conducted to define the most common obstacles encountered in recently published papers worldwide. Thus, it was possible to evaluate the relationship between the barriers cited by Brazilian specialists and those addressed by foreign researchers. Finally, Cronbach's alpha was used to attest the consistency of the research.

The main contribution of this research is the identification of the leading factors that hinder the implementation of SPPs in the Brazilian public sector. Therefore, the research findings contribute to the expansion of the body of knowledge about the subject in the country, which is extremely limited nowadays, as well as providing a valuable reference for experts and practitioners in the selection of the obstacles that must be firstly overcome to stimulate the application of SPPs.

Following this introduction, this paper is structured into five additional sectors. Section 2 presents the conceptual background of the research based on a comprehensive literature review that culminates in research questions development. Section 3 describes the details of the research methodology procedures, including sampling, data collection procedures, and research tools. Section 4 presents research findings and data analysis. Section 5 discusses the implications of the study results. Finally, Section 6 summarizes the study conclusions, as well as exposes work limitations and directions for further research. 


\section{THEORETICAL BACKGROUND}

Excessive consumption of natural resources has caused enormous environmental degradation, reaching extremely worrying levels over the years as global ecosystems are not able to regenerate at an equivalent rate to its exploitation [41],[44]. In recent decades, the subject has been increasingly occupying the international meetings agenda [45], which aims not only to mitigate environmental problems generated by this lack of control, but also to preserve society in an effort to guarantee their quality of life [41]. This set of events consolidated SPPs in the international scenario, pressing all stakeholders to face the 'reality that sustainability might no longer be a matter of choice, but a necessity' [18].

The goal of a traditional procurement is to 'find an optimal balance between quality and low costs' [2]. However, considering the increasing concern about the impact of business on society as a whole [9], factors other than economic prosperity have come to be considered by the decision-making mechanisms, such as the protection of the natural environment and social justice [40]. This is strongly associated with the concept of sustainable development [5] formulated by John Elkington [47], globally known as 3Ps, reflecting the dimensions of the triple bottom line (TBL). Based on this, procurers should consider a number of topics in their purchasing processes, which cannot be analyzed in isolation [22]. These aspects are also labeled as the three sustainability pillars: profit (economic), planet (environmental), and people (social) [16],[40].

The terms used to define SPP are often different, although all of them point out that, in essence, it is necessary to preserve a delicate balance between the economic and social aspects, and environmental conservation [45], by means of a demand-oriented policy tool [48]. Walker and Brammer [9], for instance, highlight SPP as 'the pursuit of sustainable development objectives through the purchasing and supply process, incorporating social, environmental and economic aspects'. Uttam and Roos [23] state that SPP 'specifications require a product/service with minimum or lower environmental impact and/or a positive social outcome in relation to another product/service that meets the same purpose'. The authors of [49] stated that it 'involves the purchase of any product or service that results in a lesser environmental impact while performing a similar function (to comparable products or services) and while demonstrating social responsibility and ethics, at its comparable price to enhance competitive performance'. Despite the growing inclusion of sustainable criteria in the procurement processes [18],[50], and the broader attention received by researchers worldwide [21], in many cases, however, the focus was on only one of the three pillars [40], tending to favor the environmental dimension [51], thus dismantling the concept of SPP.

Therefore, it is required that public procurers change their regular procurement behavior [7], seeking to integrate equally all sustainability pillars into organizational strategies [11]. This is indispensable given the scale of PPs [8],[52], that allows the Government to employ its purchasing power to influence buyers and sellers [5],[16],[26],[37],[53] towards a more sustainable society. According to [50], some of the benefits provided by SPP practices are the transformation of markets, job creation, monetary economy, and protection of natural resources. Thereby, SPP is already recognized as a powerful agent of change [45] and a key mechanism to drive public policies [37],[52], enabling governments to 'reduce the negative aspects of production and consumption' [7].

Although fundamental, SPP implementation presents a high level of complexity [48]. Tensions usually arise between the traditional focus on choosing the cheapest bidder and the sustainability goals [12]. As reported in [30], in cases where SPP represents cost reduction, the choice is clear, but when circumstances are not so obvious, there is a general difficulty in choosing the most advantageous tender. The situation worsens in public agencies where the 
procurement function is typically perceived as a back-end function and is rarely considered of strategic interest [54], hampering the imperative 'shift from purchase-cost to life-cycle cost approach' [11]. This is just one of the many barriers to be transposed in order to institutionalize SPPs in the public sector.

The research aims to elucidate which barriers are hindering the evolution of the SPP concept in the Brazilian public sphere and the perceived negative impact of each of them in government sustainable purchases. In order to achieve this objective, it was necessary to answer the following research questions (RQ) by means of a Delphi exercise, as outlined in the next section.

RQ1: What are the main barriers that negatively affect Brazilian sustainable public acquisitions?

RQ2: The barriers cited for the Brazilian reality are related to the barriers found in the international literature?

RQ3: What barriers must be faced first to consolidate SPPs in Brazilian public institutions?

\section{RESEARCH METHOD}

The current study adopts a methodological approach (Fig. 1) that combines quantitative and qualitative information to increase research reliability [22],[33]. Data were collected through a Delphi exercise that was used to identify the main barriers affecting SPP in the Brazilian public sector context. This approach allows for a deeper analysis of the subject [22] and contributes to the formation of a specialized collective opinion [55]. A five-point Likert scale was used to collect opinions from sustainability experts in order to identify, rank, and prioritize the barriers regarding to their level of impact from the perspective of

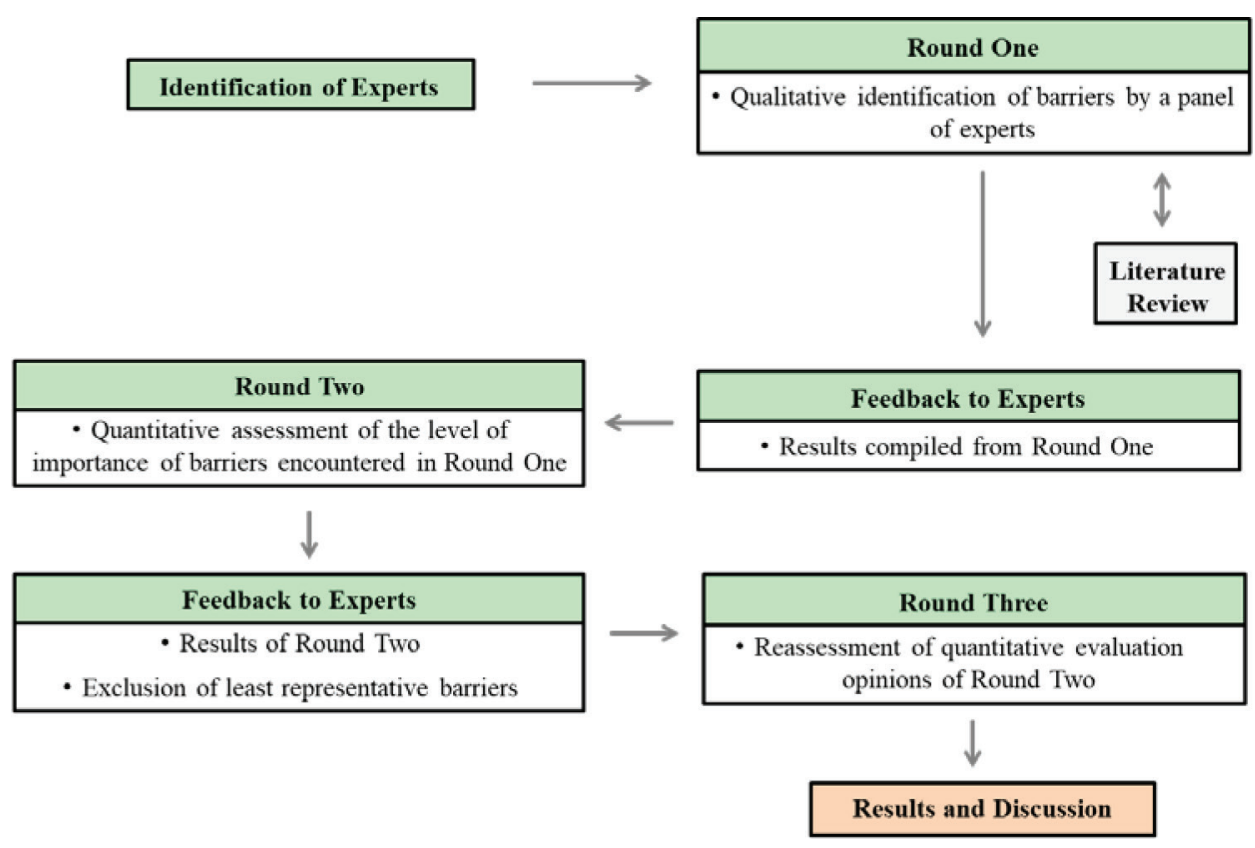

Figure 1: Study method steps. 
professionals with recognized competence. This is the most requested measurement scale in PP research [7],[9],[12],[16],[21],[26],[28],[43],[56]-[58] and the higher the average value of a barrier, the greater the perception of its overcoming complexity. Simultaneously with the Delphi study, a comprehensive literature review was carried out to define the most common barriers encountered in recent published work worldwide, allowing responses to the research questions.

The research data were analyzed using the Cronbach's alpha test to evaluate the internal consistency of the questionnaire among the responses under the adopted measure scale [41],[43],[59]. Cronbach's alpha coefficient ranges from 0 to 1.00, where 1.00 indicates the highest level of validity and reliability of the quantitative inputs [43]. Previous studies suggest that alpha scores above 0.70 are considered acceptable and, since Cronbach's alpha value is above 0.886 , the scale in this study is considered reliable and indicated that each item was unique and not a repetition [50],[60].

\subsection{Delphi study}

The Delphi method was developed in 1962 by Norman Dalkey and Olaf Helmer [61]. It consists of a group process [62] in which collective conclusion is considered more trustworthy than individual opinions [55]. The method is structured from questionnaire rounds with knowledge being transferred between the participants through feedback and survey readministration [55], which requires time commitment and a certain willingness on the part of the individuals to review their own points of view [63].

Another feature of the Delphi approach is that information can be exchanged until a satisfactory degree of consensus is reached [55], without requiring participants to meet in person [64]. In fact, maintaining the anonymity of individual responses during the process is even desirable [63], as it allows participants to express their opinions more transparently and without any fear of being judged by other members of the group.

The authors of [61]-[64] provide more in-depth information on the Delphi concept.

Given the apparent complexity of SPP, researchers chose to use in the Delphi study a panel of carefully selected sustainability experts in order to reduce results uncertainty and improve reliability. The selection criteria involved indicators of academic and professional training, years of experience working with the SPP [55], publications in the field [25], presentations made at national and international conventions [25], and availability to participate [14]. 23 recognized sustainability specialists with extensive professional experience and representing a range of sectors, such as academics, public sector professionals and consultants, were initially invited to engage in the study. 20 of them accepted the task.

Although there is some consensus in the literature that is usually between 8 and 15 experts is an acceptable amount, it was decided to invite a larger number of participants considering that some of them may give up in the middle of the process, thus affecting the validity of the study [65]. This proved to be a good strategy, of the 20 specialists who started the survey, only 17 completed the whole process (representing a response rate of $85 \%$ for the whole study). This remains a high level of responses, which was achieved by fixing the participants time commitment in three rounds, which occurred between June 5 and August 30, 2018. Although the panel was composed entirely of subject matter experts, a guide was emailed to all participants before the start of the first round of the study. This document aimed to inform about the research project and its objectives, as well as to ensure that all terms and definitions related to SPPs were interpreted in the same way. 
Then the three steps of the research were performed. The first round consisted of a single open-ended question: Which barriers hinder the application of SPPs in the Brazilian public sector? The option for this approach rather than the application of a longer questionnaire was made in order to 'facilitate the exploration of the subject' [25], keeping the focus on the theme, thus increasing the response rate. Results obtained in the first round were analyzed and the barriers cited were compiled giving rise to a new questionnaire. In the second round, respondents were asked to assess the level of importance of the 41 barriers obtained in round one, using a five-point Likert scale ranging from 1 denoting 'not critical' to 5 denoting 'very critical'. Based on this scale, the barriers were classified and the least representative ones were excluded from the study, reducing the time of completion of the questionnaire, thus encouraging continuity of participation by the specialists. In the third and last round, participants were provided with average values obtained in round two and then invited to re-evaluate their views using the same Likert scale.

All contact between the researchers and the specialists was carried out by e-mail, and respondents' answers and identities were kept anonymous to the other panel group members. The results obtained at each stage of the Delphi study are presented in Section 4 of this article, and were translated by the authors from Portuguese to English.

\section{RESULTS}

\subsection{Demographic background}

Currently, it is not easy to find professionals with great experience in sustainability and, at the same time, knowledge about procurement processes. Therefore, our sampling strategy began with a list of previous research contacts, including academics and practitioners. Initially, 38 possible participants were identified for the study. In order to reduce and refine the list of experts, it was decided to invite only those who had more than five years of professional experience and at least two years of experience in applying SPPs. Thereby, the 23 specialists invited to participate in the research were selected, 20 of whom accepted the invitation. Table 1 presents the professional profile of the respondents.

\subsection{Round one}

The first stage of the Delphi study was conducted from June 5 to June 30, 2018. 20 experts were invited to respond to the aforementioned question:

Which barriers hinder the application of SPPs in the Brazilian public sector?

No regulation was established for the preparation of responses, which allowed participants to present their views with total freedom. All the experts sent their answers by email (representing a response rate of $100 \%$ for this round) and each of them reported, on average, 14 barriers. After reading and re-reading the responses received, similar items were merged to eliminate ambiguities and the 41 main barriers (B1 to B41) that negatively affect Brazilian PP according to this panel of experts were identified (Table 2), thus responding to RQ1. Table 2 also presents the result of an extensive bibliographical research that allows one to relate the barriers cited by the panel of experts with those found in international literature. The analysis of this table points out that various barriers found by the Delphi method are mentioned several times in the researched literature. This means that most of the problems faced abroad in relation to the SPPs implementation are also perceived in Brazil, highlighting the most cited items B5, B6, B20 and B26, and allowing us to answer RQ2. 
Table 1: Key profile of the respondents.

\begin{tabular}{|c|c|c|c|c|}
\hline $\begin{array}{l}\text { Sustainability } \\
\text { Experts }\end{array}$ & $\begin{array}{l}\text { Educational } \\
\text { Background }\end{array}$ & $\begin{array}{l}\text { Professional } \\
\text { Experience }\end{array}$ & SPP Experience & Sector \\
\hline Specialist 1 & Engineer, D.Sc. & 20 years & 5 years & Construction \\
\hline Specialist 2 & Architect, M.Sc. & 8 years & 3 years & Health \\
\hline Specialist 3 & Architect, D.Sc. & 10 years & 3 years & Construction \\
\hline Specialist 4 & Engineer, $\mathrm{PhD}$ & 18 years & 6 years & Education \\
\hline Specialist 5 & Economist, M.Sc. & 5 years & 2 years & Health \\
\hline Specialist 6 & Lawyer, D.Sc. & 10 years & 5 years & Education \\
\hline Specialist 7 & Administrator, MBA & 8 years & 4 years & Health \\
\hline Specialist 8 & Architect, MBA & 12 years & 6 years & Construction \\
\hline Specialist 9 & Engineer, M.Sc. & 7 years & 4 years & Construction \\
\hline Specialist 10 & $\begin{array}{l}\text { Interior Designer, } \\
\text { M.Sc. }\end{array}$ & 8 years & 3 years & Construction \\
\hline Specialist 11 & Professor, D.Sc. & 23 years & 7 years & Education \\
\hline Specialist 12 & Professor, $\mathrm{PhD}$ & 20 years & 8 years & Education \\
\hline Specialist 13 & Administrator, M.Sc. & 10 years & 3 years & Health \\
\hline Specialist 14 & Accountant, M.Sc. & 12 years & 5 years & Health \\
\hline Specialist 15 & Engineer, M.Sc. & 5 years & 2 years & Construction \\
\hline Specialist 16 & Professor, D.Sc. & 16 years & 5 years & Education \\
\hline Specialist 17 & Professor, D.Sc. & 18 years & 6 years & Education \\
\hline Specialist 18 & $\begin{array}{l}\text { Interior Designer, } \\
\text { MBA }\end{array}$ & 6 years & 3 years & Construction \\
\hline Specialist 19 & Architect, M.Sc. & 12 years & 5 years & Construction \\
\hline Specialist 20 & Engineer, D.Sc. & 14 years & 6 years & Construction \\
\hline
\end{tabular}

Table 2: Barriers identified in Delphi first round and in the international literature.

\begin{tabular}{clc}
\hline Code & Barrier & Literature References \\
\hline B1 & Lack of financial support & {$[5],[24],[30],[33],[38]$} \\
B2 & Decentralized purchasing structures & {$[5],[60]$} \\
& Insufficient integration between suppliers and pur- & {$[24],[25],[30],[67]$} \\
B3 & chasers & {$[66]-[68]$} \\
B4 & Excessive bureaucracy & {$[5],[21],[24],[30],[31]$,} \\
& Higher costs/prices resulting from the option for & {$[38],[42],[60],[66]$} \\
B5 & sustainable items & {$[24],[33],[42],[66],[68]$} \\
B6 & Lack of government incentives & {$[38]$} \\
B7 & Rigid organizational structure of public institutions & \\
\hline
\end{tabular}




\begin{tabular}{|c|c|c|}
\hline Code & Barrier & Literature References \\
\hline $\mathrm{B} 8$ & Disarticulation between the spheres of public sector & {$[38]$} \\
\hline B9 & $\begin{array}{l}\text { Conflicts between the priorities of the purchasing } \\
\text { process (economic, social, and environmental) }\end{array}$ & {$[5],[38],[60]$} \\
\hline B10 & $\begin{array}{l}\text { Instability generated by electoral cycles that can dis- } \\
\text { rupt government SPP initiatives }\end{array}$ & {$[5],[38],[60]$} \\
\hline B11 & Lack of long-term planning & [5], [21], [24], [38], [67] \\
\hline B12 & Lack of procurer awareness & [5], [24], [31], [33], [38] \\
\hline B13 & Lack of supplier awareness & [5], [24], [31], [33], [60] \\
\hline B14 & $\begin{array}{l}\text { Lack of clear organizational guidelines and strategic } \\
\text { goals for the application of SPPs }\end{array}$ & $\begin{array}{l}{[24],[25],[30],[31]} \\
{[38],[67]}\end{array}$ \\
\hline B15 & Lack of transparency in procurement decision making & {$[25]$} \\
\hline B16 & Lack of methods to measure sustainability & {$[25],[33]$} \\
\hline B17 & Tendency to maintain current practices & [21], [24], [33], [67] \\
\hline B18 & $\begin{array}{l}\text { Concerns about the quality of sustainable products/ } \\
\text { services }\end{array}$ & {$[5],[38],[60]$} \\
\hline B19 & Lack of attractiveness of sustainable products/services & {$[24],[42]$} \\
\hline $\mathrm{B} 20$ & $\begin{array}{l}\text { Insufficient/Inconsistent government policies and } \\
\text { regulations that encourage SPP }\end{array}$ & $\begin{array}{l}{[21],[24],[30],[33]} \\
{[38],[60],[67]}\end{array}$ \\
\hline B21 & Countries social, economic and political context & {$[67]$} \\
\hline B22 & Lack of knowledge of local conditions & {$[33]$} \\
\hline $\mathrm{B} 23$ & $\begin{array}{l}\text { Perception that the option for sustainable items can } \\
\text { restrict competition }\end{array}$ & [5], [38] \\
\hline B24 & Lack of public/citizen pressure & {$[30]$} \\
\hline $\mathrm{B} 25$ & Lack of policy makers support & {$[5],[60],[67]$} \\
\hline B26 & Lack of top management support & [24], [30], [31], [33], [60] \\
\hline $\mathrm{B} 27$ & $\begin{array}{l}\text { Low availability of sustainable products/services sup- } \\
\text { pliers }\end{array}$ & [5], [30], [38], [60] \\
\hline B28 & $\begin{array}{l}\text { Lack of knowledge on the existence of sustainable } \\
\text { items suppliers }\end{array}$ & {$[38]$} \\
\hline B29 & $\begin{array}{l}\text { Lack of sustainable products/services available on } \\
\text { market }\end{array}$ & {$[5],[38],[42],[60]$} \\
\hline B30 & $\begin{array}{l}\text { Insufficient integration of sustainability requirements } \\
\text { into contract specifications }\end{array}$ & {$[5],[25],[60]$} \\
\hline B31 & $\begin{array}{l}\text { Inconsistent definitions and different interpretations of } \\
\text { the SPP concept }\end{array}$ & {$[24],[30],[33]$} \\
\hline B32 & Lack of procurers training and education to adopt SPP & $\begin{array}{c}{[25],[30],[31],[38]} \\
{[66],[67]}\end{array}$ \\
\hline B33 & Lack of suppliers training and education to adopt SPP & {$[21],[30],[31],[38],[67]$} \\
\hline
\end{tabular}




\begin{tabular}{|c|c|c|}
\hline B34 & $\begin{array}{l}\text { Insufficient R\&D background on sustainable tech- } \\
\text { nologies }\end{array}$ & {$[24],[68]$} \\
\hline B35 & $\begin{array}{l}\text { Lack of knowledge about the social and environmen- } \\
\text { tal impacts of sustainable products }\end{array}$ & {$[30]$} \\
\hline B36 & $\begin{array}{l}\text { Bad previous experiences in purchasing sustainable } \\
\text { items }\end{array}$ & {$[42]$} \\
\hline B37 & $\begin{array}{l}\text { Lack of sufficient time to incorporate sustainable } \\
\text { items in the procurement process }\end{array}$ & {$[5],[24],[38],[60]$} \\
\hline B38 & $\begin{array}{l}\text { Complexity in incorporating sustainability concepts } \\
\text { into the purchasing process }\end{array}$ & {$[31]$} \\
\hline B39 & $\begin{array}{l}\text { Difficulty in considering the cost of the whole product } \\
\text { /service life cycle in tender evaluation }\end{array}$ & [25], [33] \\
\hline B40 & Slow and inefficient dissemination of SPP knowledge & {$[24],[33],[42],[66]$} \\
\hline B41 & Lack of organizational culture to support SPP & {$[24],[38],[60]$} \\
\hline
\end{tabular}

\subsection{Round two}

This round was conducted from July 9 to July 31, 2018. The same 20 experts were invited to complete this new questionnaire, but only 19 replies were received (representing a response rate of $95 \%$ for this round). One expert was not able to respond due to workload, which did not affect sample representativeness. At this stage, respondents received a spreadsheet containing the 41 barriers pointed out in the first round and were asked to classify their level of importance according to a five-point Likert scale ranging from 1 denoting 'not critical' to 5 denoting 'very critical'. All items were presented in the form of sliders permitting participants to 'indicate their preferences by sliding along the scale rather than choosing just one of the five options' [18]. This allowed experts to judge each barrier with the greatest possible criterion.

The results analysis enabled the identification of the 41 barriers statistical significance. Barriers with mean values below 2.00 were considered not significant (based on the Likert scale used) and were excluded from the study. This was done in order to eliminate the less representative items and ensure that the final list reflects the opinion of most experts on barriers that are really relevant in the Brazilian context, since this is the main goal of this Delphi exercise.

The calculated standard deviation for each barrier can be considered low given the sample size, indicating harmony among the experts' opinions. It is also important to note that the highest standard deviations were observed in the barriers that were excluded from the study because of their low average (below 2.00), indicating a lack of uniformity in the responses. This means that few experts considered these barriers to be really relevant to the Brazilian context. Nine barriers were removed, among which: lack of public/citizen pressure (B24); lack of knowledge about the existence of sustainable items suppliers (B28); concerns about the quality of sustainable products/services (B18); lack of supplier awareness (B13); lack of attractiveness of sustainable products/services (B19); unfavorable social, economic, and political context of the country (B21); instability generated by electoral cycles that can disrupt government SPP initiatives (B10); disarticulation between the spheres of public sector (B8); and lack of knowledge of local conditions (B22). 


\subsection{Round three}

The third and last round was conducted from August 6 to August 30, 2018. Considering the 19 specialists who completed the second step of the study, 17 presented their answers in this third round (representing a response rate of $89.5 \%$ for this round). Two experts were not able to respond due to workload, which did not affect the sample representativeness.

At this stage a new questionnaire was developed. The less representative items were excluded and respondents were provided with average values for the Likert scales by means of a sheet with two scores. The first one was named 'Your score' and represented the score that the expert provided in round two, and the second score was named 'Mean score' and represented the mean of the scores provided by all the experts in round two [25]. Based on this information participants were then invited to re-evaluate their views using the same five-point Likert scale. Table 3 shows the classification found according to the new calculated averages and also the new standard deviation of the scores obtained for each of the evaluated items.

Indeed, on average, the standard deviations were maintained, indicating a low variation in the experts opinions. Thus, the main changes resulting from Delphi third round were minor modifications in the barriers classification, highlighting those occurred among the 10 most cited ones, such as: B41 was originally placed in the fourth position and at the end of the third round was moved to the sixth position; B26 which was in 11th went down to ninth place; and B6 climbed one position down, moving from the eighth to the seventh place.

Table 3: Barriers classification after Delphi third round.

\begin{tabular}{|c|c|c|c|c|}
\hline Rank & \multicolumn{2}{|c|}{ Barrier } & $\begin{array}{l}\text { Mean } \\
\text { Value }\end{array}$ & $\begin{array}{l}\text { Standard } \\
\text { Deviation }\end{array}$ \\
\hline 1 & B11 & Lack of long-term planning & 4.84 & 0.177 \\
\hline 2 & B16 & Lack of methods to measure sustainability & 4.79 & 0.178 \\
\hline 3 & B35 & $\begin{array}{l}\text { Lack of knowledge about the social and environ- } \\
\text { mental impacts of sustainable products }\end{array}$ & 4.78 & 0.198 \\
\hline 4 & B32 & $\begin{array}{l}\text { Lack of procurers training and education to adopt } \\
\text { SPP }\end{array}$ & 4.69 & 0.231 \\
\hline 5 & B33 & $\begin{array}{l}\text { Lack of suppliers training and education to adopt } \\
\text { SPP }\end{array}$ & 4.68 & 0.216 \\
\hline 6 & B41 & Lack of organizational culture to support SPP & 4.58 & 0.267 \\
\hline 7 & B6 & Lack of government incentives & 4.53 & 0.355 \\
\hline 8 & B5 & $\begin{array}{l}\text { Higher costs/prices resulting from the option for } \\
\text { sustainable items }\end{array}$ & 4.51 & 0.105 \\
\hline 9 & B26 & Lack of top management support & 4.36 & 0.589 \\
\hline 10 & B23 & $\begin{array}{l}\text { Perception that the option for sustainable items can } \\
\text { restrict competition }\end{array}$ & 4.34 & 0.490 \\
\hline 11 & B20 & $\begin{array}{l}\text { Insufficient/Inconsistent government policies and } \\
\text { regulations that encourage SPP }\end{array}$ & 4.28 & 0.555 \\
\hline 12 & B39 & $\begin{array}{l}\text { Difficulty in considering the cost of the whole prod- } \\
\text { uct /service life cycle in tender evaluation }\end{array}$ & 4.19 & 0.675 \\
\hline
\end{tabular}




\begin{tabular}{|c|c|c|c|c|}
\hline 13 & B14 & $\begin{array}{l}\text { Lack of clear organizational guidelines and strate- } \\
\text { gic goals for the application of SPPs }\end{array}$ & 4.12 & 0.305 \\
\hline 14 & B30 & $\begin{array}{l}\text { Insufficient integration of sustainability require- } \\
\text { ments into contract specifications }\end{array}$ & 4.11 & 0.448 \\
\hline 15 & B3 & $\begin{array}{l}\text { Insufficient integration between suppliers and } \\
\text { purchasers }\end{array}$ & 4.03 & 0.668 \\
\hline 16 & B38 & $\begin{array}{l}\text { Complexity in incorporating sustainability concepts } \\
\text { into the purchasing process }\end{array}$ & 3.95 & 0.529 \\
\hline 17 & B29 & $\begin{array}{l}\text { Lack of sustainable products/services available on } \\
\text { market }\end{array}$ & 3.88 & 0.467 \\
\hline 18 & $\mathrm{~B} 27$ & $\begin{array}{l}\text { Low availability of sustainable products/services } \\
\text { suppliers }\end{array}$ & 3.81 & 0.631 \\
\hline 19 & B9 & $\begin{array}{l}\text { Conflicts between the priorities of the purchasing } \\
\text { process (economic, social and environmental) }\end{array}$ & 3.69 & 0.810 \\
\hline 20 & B25 & Lack of policy makers support & 3.62 & 0.775 \\
\hline 21 & B34 & $\begin{array}{l}\text { Insufficient R\&D background on sustainable tech- } \\
\text { nologies }\end{array}$ & 3.52 & 0.420 \\
\hline 22 & B15 & $\begin{array}{l}\text { Lack of transparency in procurement decision mak- } \\
\text { ing }\end{array}$ & 3.33 & 0.584 \\
\hline 23 & B17 & Tendency to maintain current practices & 3.22 & 0.311 \\
\hline 24 & B4 & Excessive bureaucracy & 3.18 & 0.439 \\
\hline 25 & B1 & Lack of financial support & 3.15 & 0.843 \\
\hline 26 & B31 & $\begin{array}{l}\text { Inconsistent definitions and different interpretations } \\
\text { of the SPP concept }\end{array}$ & 3.10 & 0.671 \\
\hline 27 & B12 & Lack of procurer awareness & 3.08 & 0.781 \\
\hline 28 & B2 & Decentralized purchasing structures & 3.05 & 0.840 \\
\hline 29 & B36 & $\begin{array}{l}\text { Bad previous experiences in purchasing sustainable } \\
\text { items }\end{array}$ & 2.96 & 0.924 \\
\hline 30 & B37 & $\begin{array}{l}\text { Lack of sufficient time to incorporate sustainable } \\
\text { items in the procurement process }\end{array}$ & 2.69 & 0.989 \\
\hline 31 & B40 & $\begin{array}{l}\text { Slow and inefficient dissemination of SPP knowl- } \\
\text { edge }\end{array}$ & 2.55 & 0.909 \\
\hline 32 & B7 & Rigid organizational structure of public institutions & 2.14 & 0.914 \\
\hline
\end{tabular}

\section{DISCUSSION}

Table 3 above shows the classification of barriers that prevent the dissemination of SPPs according to the level of importance assigned by a panel of experts specially selected for this study. At first sight, it is possible to notice that barriers present high averages, that is, most of the barriers obtained mean values above $4(42.87 \%)$ in a scale ranging from 1 to 5 , indicating that there is consensus about the severity of the difficulties faced in the implementation of SPPs in the Brazilian public sector. Another relevant factor to be observed is the distribution 
of the standard deviation in the study. The deviations presented in each of the barriers varied between 0.105 and 0.989 , values considered within the normal parameters for studies of this category [38].

However, it is in the upper and lower extremities of Table 3 that the most important contributions of this research are located. First, it is worth noting the lower end of the list where the least voted barriers are located. From the experts group perspective the slow and inefficient dissemination of SPP knowledge (B40) and the rigid organizational structure of public institutions (B7), are not fundamental problems for the advancement of SPPs in Brazil. This is a very important fact because it shows that experts do not believe that the lack of information about the importance of sustainability in PP or a possible hierarchical rigidity in the organizational chart of the institutions are sufficiently serious factors to prevent the implementation of sustainable criteria in the biddings.

The upper row of the table, in turn, presents the most relevant result of this research. The 10 best classified barriers were considered very critical by the experts, and this result is significant, since it identifies the challenges that must be faced first to consolidate SPPs in Brazilian public institutions, answering RQ3. Thus, these 10 items will be analyzed below.

\section{- Lack of long-term planning (B11) and higher costs/prices resulting from the option for sustainable items (B5)}

Increasing costs/prices is one of the factors most frequently identified as an obstacle to SPPs implementation [2],[5],[8],[21],[34],[60]. In fact, this barrier ranked 8th in the Delphi Study, with a mean value of 4.51 , and it is completely related to the long-term planning, which was the most well-ranked barrier in this study, with a mean value of 4.84 (Table 3 ).

Actually, the incorporation of modern technologies or the use of higher quality raw materials, usually the basic conditions for new products creation, are the main causes of the higher cost presented by items that manifest sustainable characteristics [30] and difficulty in finding qualified suppliers to provide a specific product or service [15]. However, this is a very common phenomenon in the consumer market of virtually all sectors of the economy. A smartphone, for example, may have its sale price doubled over the previous model as a result of a processor upgrade or due to the inclusion of a higher resolution camera. The question is, therefore, why such overvaluation is considered trivial, while the use of more money in the purchase of products less harmful to the environment or that promote social benefits is still seen by many as an affront to the principle of economicity.

The lowest price paradigm, coming from the traditional perspective of cost reduction at any price [12], still needs to be broken. Purchasers, in general, continue to superficially compare elements to be acquired, completely ignoring the cost-benefit notion. A currently more expensive item may, in medium or long term [30], offsets the initial costs incurred in buying [17], due to factors such as, saving water and energy, improving users quality of life and reducing negative impacts to the natural and human environment. As long as these externalities are not included in the equation, sustainable items will continue to be neglected because they are considered too expensive in relation to traditional items.

- Lack of methods to measure sustainability (B16) and Lack of knowledge about the social and environmental impacts of sustainable products (B35)

These barriers ranked 2nd and 3rd in the Delphi Study, with a mean value of 4.79 and 4.78 , respectively (Table 3). Indeed, much of the failure to disseminate SPPs has been attributed to the 
lack of means to determine whether a declared 'sustainable' item is, in fact, more advantageous than a 'traditional' one [23],[27],[46]. Therefore, if a strategy is not widely implemented to accurately inform the degree of sustainability of a particular product or service, it is really difficult to determine concretely its positive or negative impacts on the environment and society. Actually, this kind of labeling is somewhat unfortunate because it polarizes objects in an inappropriate way. No product or service is fully sustainable, and it is not always possible to categorize it as totally unsustainable. Almost all fit into a middle ground, where some have specific characteristics that, according to some standards, allow them to get the stereotype of a socio-environmentally friendly product or service. However, the lack of reliable references, in some cases, results in misjudgments, favoring articles whose profitability does not last in the long term.

There is an urgent need to recognize and adopt metrics that allow wide-spectrum analyzes, that is, that identify and quantify the impacts and costs caused by the production of an item, which must cover the entire production chain, including its manufacturing, storage , transport, use, and final destination, i.e. a cradle-to-cradle system [23]. In this perspective, one of the most promising tools is the life cycle assessment (LCA) [15]. Standardized by ISO 14040, it is a technique for analyzing the environmental performance of products and services throughout their life cycle. Thereby, it becomes evident the viability of items comparison by means of a clear and scientifically based method, providing security to the manager in the choice of an object that produces less negative impact to the environment [30]. The use of this technique will allow the verification of which item presents more compatible characteristics with the aspirations of the Government, driving the choice of the most advantageous object and eliminating any subjectivity in the judgment. That is the only way to certify that all costs involved in the generation of a product or service is being considered, allowing its apportionment throughout its useful life. This is an essential condition for measuring profitability, since unfortunately the average consumer tends to present a superficial understanding of object cost assessment, tending to opt for those with lower initial expenses, whereas, in fact, others values must be taken into account [7].

\section{- Lack of procurers and suppliers training and education to adopt SPP (B32 and B33)}

This is one of the main reasons pointed out by professionals who work in the area for not using the sustainable criteria in their licitatory processess [41] and, in this research, ranked 4th and 5th among the most critical barriers in the Delphi study, with a mean value of 4.69 and 4.68 (Table 3). In fact, the scarce existing literature on SPPs [16] contributes to the lack of current technical capacity [15],[30], constituting a limiting factor for activities effective performance in any area. However, although it is a legitimate restrictive aspect, it does not represent an argument that grounds its non-observation. It is a professional duty to permanently search for information that helps to perform its functions in the most efficient way possible, acquiring technical competences to perform SPPs [31]. It is not expected that all professionals will instantly become experts in the socio-environmental analysis of the wide range of products and services acquired by the institutions in which they operate, but at least, in principle, be capable of identifying, pondering, and describing the most important criteria for the most prominent objects [30].

\section{- Lack of organizational culture to support SPP (B41)}

The generalization of the application of sustainable criteria in the procurement process represents a common challenge for all the professionals involved in the acquisition of products 
and services for the Public Power, who must be willing to remodel their traditional concepts of purchase [16]. That is the reason for this barrier to stay in the sixth place in the Delphi study list, with a mean value of 4.58 (Table 3 ).

The values adopted by the institution become especially significant [15], since they emphasize the organization's perspective regarding the objectives of restricting environmental degradation and increasing social responsibility in its contracting, the latter being considered here as the use of purchasing power in the acquisition of products and services with a positive social impact [23]. However, new convictions are not always easily embedded in an industry typically marked by decades of stagnation [48]. Therefore, it is imperative the involvement of these organizations leaders in the company cultural mutation process, since they are responsible for determining the methodology to be adopted [41].

\section{- Lack of government incentives (B6)}

Incentive policies are considered valid and direct methods of accelerating the adoption of sustainable systems [57]. Unfortunately, for a large part of society, which includes public administrators, socio-environmental protection is still appreciated through a blurred lens, which has a direct and negative impact on the understanding of the sustainable national development principle in PP. Despite this, B6 ranked seventh in the Delphi Study with a mean value of 4.53 (Table 3 ). In order to reach an acceptable scale, it is essential to formulate an ostensible awareness program, which can only be achieved through a scenario of solid political support.

It is therefore perceptible that the participation of the State is imperative [69], either indirectly, when exercising its role of buyer, using its massive purchasing power for the introduction of public policies [8],[27],[48], or actively, directly financing the expansion of a new consumer and producer market, in line with the notion of public interest in protecting the natural and human environment [30].

\section{- Lack of top management support (B26)}

This barrier ranked 9th in the Delphi study, with a mean value of 4.36 (Table 3). Contrary to the small innovations that normally originate in the 'factory floor', the formulation of a new policy that breaks paradigms and influences an entire corporation will hardly be realized by an employee allocated at the heart of the productive chain, but through the commitment of the company leaders [41],[30], whose managerial vision will enable the establishment of new guidelines and results collection, never forgetting the crucial institutionalization of these policies, in order to transcend the current leadership. This is an indispensable precaution in a country whose notion of development is often tied to party's whims.

\section{- Perception that the option for sustainable items can restrict competition (B23)}

There is a false perception that the exclusion of companies from a bidding process due to the non-compliance of one or more sustainable clauses imposed by the Government represents a restriction to the competitiveness of the event [16], since reducing the number of participants limits the benefits that could be achieved through a wider competition. This erroneous notion put this barrier in the tenth place of the Delphi study list, with a mean value of 4.34 (Table 3 ). In fact, a procurement process suggests the existence of a relative assortment of organizations, which could possibly be interested in disputing the contract in question, thus allowing 
the selection of the most advantageous proposal for the contracting institution. However, the urgency of attracting as many candidates as possible cannot be considered more important than the purchase of the object that best meets the collective interest.

In this sense, procurers' responsibility increases, since they must clearly and objectively specify the item to be acquired, aiming firstly to meet the needs of the institution and compliance with the legislation, even though, the group able to compete is diminished. Therefore, in addition to the need for a correct description of the item to be tendered, continuously proactive attitude is expected from procurers, looking for information on the products that are already available in the market, so that they can indicate to their suppliers what will be required in future biddings, facilitating their adaptation.

\section{CONCLUSION}

Several challenges of implementing SPPs have been suggested in the literature [30],[60], and an increasing amount of scholars have been devoting themselves to the study of its barriers [28]. This phenomenon indicates that there is a growing consensus on the relevance of the role of the public sector as a promoter of sustainable policies [9]. In this sense, considering the scarcity of studies on SPPs in underdeveloped and developing countries, this research consolidates as one of the first to effectively assess the obstacles making it difficult in its implementation in Brazilian context. The research findings not only significantly increase the existing body of knowledge on SPPs, but also provide empirical support for the selection of the barriers that must be overcome in the first place to stimulate the application of sustainable purchases in the Brazilian public sector.

This study successfully answered the three research questions providing practical implications for public procurers, researchers, and policymakers. Procurers' behavior is crucial [28], because they are the frontline professionals whose decisions can directly influence how the institution addresses sustainability in its purchasing policy. However, only through the constant search for qualification, servers in general will permanently dispel any fear of facing potential legal conflicts, which is a risk aversion behavior that has reduced the willingness of these professionals to participate in innovative projects [7]. Researchers need to focus their attention on developing methods and tools to measure the sustainability of products and services, providing a solid technical base for procurers, so that they can always choose the most advantageous item. On the other hand, policymakers should introduce clear and simple instructions on SPPs into government programs in order to legally justify procurers' choice. Thus, the empirical and theoretical results of this research lead to the conclusion that a single individual is not able to reach the objectives of the SPPs working alone. A joint action of all the categories of professionals involved in the subject is necessary, so that the obstacles indicated in this study can be overcome, one by one.

This research is subjected to some limitations that should be considered, and some may serve as a stimulus for future work. The research design provides a snapshot of SPP practices in the Brazilian context. Therefore, further studies could test the applicability of results in different underdeveloped and developing countries. The research findings are clearly limited in terms of sample size. Although a satisfactory number of experts participated in the research, generalization of results should be done with caution, since it may not represent the entire population. A larger sample may be considered in future studies to overcome this problem. Associated with this limitation is the fact that the geographical distribution of the sample was made unevenly. In fact, the opinions of experts could be influenced by cultural differences, however, this is a common factor in a continental country such as Brazil, and the investigation of these differences was not included in the scope of the article. For 
future research, it would be interesting to examine the opinion of specialists in different regions separately.

Finally, current research can be extended in several directions, however, it is important to highlight the need to consider the suppliers perspective on the subject, since this study took into account only the procurers' opinion. Therefore, this article provides suggestions for future research by shedding light on the most cited barriers by SPP experts and, it is hoped that it can promote the improvement of SPP practices in Brazil.

\section{REFERENCES}

[1] Sparrevik, M., Wangen, H.F., Fet, A.M. \& De Boer, L., Green public procurement A case study of an innovative building project in Norway. Journal of Cleaner Production, 188, pp. 879-887, 2018. https://doi.org/10.1016/j.jclepro.2018.04.048

[2] Aldenius, M. \& Khan, J., Strategic use of green public procurement in the bus sector: Challenges and opportunities. Journal of Cleaner Production, 164, pp. 250-257, 2017. http://doi.org/10.1016/j.jclepro.2017.06.196

[3] Pacheco-Blanco, B. \& Bastante-Ceca, M.J., Green public procurement as an initiative for sustainable consumption. An exploratory study of Spanish public universities. Journal of Cleaner Production, 133, pp. 648-656, 2016. http://doi.org/10.1016/j. jclepro.2016.05.056

[4] Uyarra, E. \& Flanagan, K., Understanding the innovation impacts of public procurement. European Pllaning Studies, 18(1), pp. 123-143, 2010. https://doi. org/10.1080/09654310903343567

[5] Walker, H. \& Brammer, S., Sustainable procurement in the United Kingdom public sector. Supply Chain Management, 14(2), pp. 128-137, 2009. https://doi. org/10.1108/13598540910941993

[6] Uyarra, E., Edler, J., Garcia-Estevez, J., Georghiou, L. \& Yeow, J., Barriers to innovation through public procurement: A supplier perspective. Technovation, 34(10), pp. 631-645, 2014. http://doi.org/10.1016/j.technovation.2014.04.003

[7] Grandia, J., Finding the missing link: examining the mediating role of sustainable public procurement behaviour. Journal of Cleaner Production, 124, pp. 183-190, 2016. http://doi.org/10.1016/j.jclepro.2016.02.102

[8] Brammer, S. \& Walker, H., Sustainable procurement in the public sector: an international comparative study. International Journal of Operations \& Production Management, 31(4), pp. 452-476, 2011. http://doi.org/10.1108/01443571111119551

[9] Walker, H. \& Brammer, S., The relationship between sustainable procurement and e-procurement in the public sector. International Journal of Production Economics, 140(1), pp. 256-268, 2012. http://doi.org/10.1016/j.ijpe.2012.01.008

[10] Witjes, S. \& Lozano, R., Towards a more Circular Economy: Proposing a framework linking sustainable public procurement and sustainable business models. Resources, Conservation and Recycling, 112, pp. 37-44, 2016. http://doi.org/10.1016/j.resconrec.2016.04.015

[11] Trindade, P.C., Antunes, P. \& Partidário, P., SPP toolbox: supporting sustainable public procurement in the context of socio-technical transitions. Sustainability, 10(2), p. 67, 2018. http://doi.org/10.3390/su10010067

[12] Keulemans, S. \& Van de Walle, S., Cost-effectiveness, domestic favouritism and sustainability in public procurement: A comparative study of public preferences. International Journal of Public Sector Management, 30(4), pp. 328-341, 2017. http://doi. org/10.1108/IJPSM-10-2016-0169 
[13] Zhu, Q., Geng, Y. \& Sarkis, J., Motivating green public procurement in China: An individual level perspective. Journal of Environmental Management, 126, pp. 85-95, 2013. https://doi.org/10.1016/j.jenvman.2013.04.009

[14] Sanchez, A.X., Lehtiranta, L., Hampson, K.D. \& Kenley, R., Evaluation framework for green procurement in road construction. Smart and Sustainable Built Environment, 3(2), pp. 153-169, 2014. http://doi.org/10.1108/SASBE-05-2013-0028

[15] Testa, F., Annunziata, E., Iraldo, F. \& Frey, M., Drawbacks and opportunities of green public procurement: an effective tool for sustainable production. Journal of Cleaner Production, 112, pp. 1893-1900, 2016. http://doi.org/10.1016/j.jclepro.2014.09.092

[16] Meehan, J. \& Bryde, D.J., A field-level examination of the adoption of sustainable procurement in the social housing sector. International Journal of Operations \& Production Management, 35, pp. 982-1004, 2015. http://doi.org/10.1108/IJOPM-07-2014-0359

[17] Bag, S., Identification of green procurement drivers and their interrelationships using total interpretive structural modelling. Vision, 21(2), pp. 129-142, 2017. http://doi. org/10.1177/0972262917700990

[18] Roman, A.V., Institutionalizing sustainability: A structural equation model of sustainable procurement in US public agencies. Journal of Cleaner Production, 143, pp. 1048 1059, 2017. http://doi.org/10.1016/j.jclepro.2016.12.014

[19] Rizzi, F., Frey, M., Testa, F. \& Appolloni, A., Environmental value chain in green SME networks: the threat of the Abilene paradox. Journal of Cleaner Production, 85, pp. 265-275, 2014. https://doi.org/10.1016/j.jclepro.2014.09.001

[20] Walker, H. \& Jones, N., Sustainable supply chain management across the UK private sector. Supply Chain Management, 17(1), pp. 15-28, 2012. https://doi. org/10.1108/13598541211212177

[21] Durdyev, S., Zavadskas, E.K., Thurnell, D., Banaitis, A. \& Ihtiyar, A., Sustainable construction industry in cambodia: awareness, drivers and barriers. Sustainability, 10(2), p. 392, 2018. http://doi.org/10.3390/su10020392

[22] Renukappa, S., Akintoye, A., Egbu, C. \& Suresh, S., Sustainable procurement strategies for competitive advantage: an empirical study. Proceedings of the Institution of Civil Engineers - Management, Procurement and Law, 169(1), pp. 17-25, 2016. http://doi. org/10.1680/jmapl.15.00006

[23] Uttam, K. \& Roos, C.L.L., Competitive dialogue procedure for sustainable public procurement. Journal of Cleaner Production, 86, pp. 403-416, 2015. http://doi. org/10.1016/j.jclepro.2014.08.031

[24] Sourani, A. \& Souhail, M., Barriers to addressing sustainable construction in public procurement strategies. Proceedings of the Institution of Civil Engineers - Engineering Sustainability, 164(4), pp. 229-237, 2011. http://doi.org/10.1680/ ensu.2011.164.4.229

[25] Sourani, A. \& Souhail, M., Enabling sustainable construction in UK public procurement. Proceedings of the Institution of Civil Engineers - Management, Procurement and Law, 166(6), pp. 297-312, 2013. http://doi.org/10.1680/mpal.12.00022

[26] Meehan, J. \& Bryde, D.J., Procuring sustainably in social housing: The role of social capital. Journal of Purchasing and Supply Management, 20(2), pp. 74-81, 2014. http:// doi.org/10.1016/j.pursup.2014.01.002

[27] Fuentes-Bargues, J.L., González-Cruz, M.C. \& González-Gaya, C., Environmental Criteria in the Spanish Public Work Procurement Process. International Journal of Environmental Research and Public Health, 14(2), 204, 2017. http://doi.org/10.3390/ ijerph14020204 
[28] Grandia, J., Steijn, B. \& Kuipers, B., It is not easy being green: increasing sustainable public procurement behaviour. Innovation-Abingdon, 28(3), pp. 243-260, 2015. http:// doi.org/10.1080/13511610.2015.1024639

[29] Simcoe, T. \& Toffel, M.W., Government green procurement spillovers: Evidence from municipal building policies in California. Journal of Environmental Economics and Management, 68(3), pp. 411-434, 2014. http://doi.org/10.1016/j.jeem.2014.09.001

[30] Ahsan, K. \& Rahman, S., Green public procurement implementation challenges in Australian public healthcare sector. Journal of Cleaner Production, 152, pp. 181-197, 2017. http://doi.org/10.1016/j.jclepro.2017.03.055

[31] Mosgaard, M.A., Improving the practices of green procurement of minor items. Journal of Cleaner Production, 90, pp. 264-274, 2015. http://doi.org/10.1016/j.jclepro.2014.11.077

[32] Rainville, A., Standards in green public procurement - A framework to enhance innovation. Journal of Cleaner Production, 167, pp. 1029-1037, 2017. http://doi. org/10.1016/j.jclepro.2016.10.088

[33] Ruparathna, R. \& Hewage, K., Sustainable procurement in the Canadian construction industry: current practices, drivers and opportunities. Journal of Cleaner Production, 109, pp. 305-314, 2015. http://doi.org/10.1016/j.jclepro.2015.07.007

[34] Mansi, M., Sustainable procurement disclosure practices in central public sector enterprises: Evidence from India. Journal of Purchasing and Supply Management, 21(2), pp. 125-137, 2015. http://doi.org/10.1016/j.pursup.2014.12.002

[35] Wang, C., Ghadimi, P., Lim, M.K. \& Tseng, M., A literature review of sustainable consumption and production: A comparative analysis in developed and developing economies. Journal of Cleaner Production, 206, pp. 741-754, 2019. http://doi.org/10.1016/j. jclepro.2018.09.172

[36] Spaargaren, G., Theories of practices: Agency, technology, and culture: Exploring the relevance of practice theories for the governance of sustainable consumption practices in the new world-order. Global Environmental Change, 21(3), pp. 813-822, 2011. http://doi.org/10.1016/j.gloenvcha.2011.03.010

[37] Aragão, C.G. \& Jabbour, C.J.C., Green training for sustainable procurement? Insights from the Brazilian public sector. Industrial and Commercial Trainning, 49(1), pp. 48-54, 2017. http://doi.org/10.1108/ICT-07-2016-0043

[38] Delmonico, D., Jabbour, C.J.C., Pereira, S.C.F., Jabbour, A.B.L.S., Renwick, D.W.S. \& Thomé, A.M.T., Unveiling barriers to sustainable public procurement in emerging economies: Evidence from a leading sustainable supply chain initiative in Latin America. Resources, Conservation and Recycling, 134, pp. 70-79, 2018. http://doi. org/10.1016/j.resconrec.2018.02.033

[39] Oliveira, B.C.S.C.M. \& Santos, L.M.L., Public procurement as a policy for sustainable development. Revista de Administração Pública, 49(1), pp. 189-206, 2015. http://doi. org/10.1590/0034-76121833

[40] Aktin, T. \& Gergin, Z., Mathematical modelling of sustainable procurement strategies: three case studies. Journal of Cleaner Production, 113, pp. 767-780, 2016. http://doi. org/10.1016/j.jclepro.2015.11.057

[41] Wong, J.K.W., Chan, J.K.S. \& Wadu, M.J., Facilitating effective green procurement in construction projects: An empirical study of the enablers. Journal of Cleaner Production, 135, pp. 859-871, 2016. http://doi.org/10.1016/j.jclepro.2016.07.001

[42] Shen, L., Zhang, Z. \& Long, Z., Significant barriers to green procurement in real estate development. Resources, Conservation and Recycling, 116, pp. 160-168, 2017. http:// doi.org/10.1016/j.resconrec.2016.10.004 
[43] Chan, A.P.C., Darko, A. \& Ameyaw, E.E., Strategies for promoting green building technologies adoption in the construction industry - an international study. Sustainability, 9(6), 969, 2017. http://doi.org/10.3390/su9060969

[44] Brooks, A. \& Rich, H. Sustainable construction and socio-technical transitions in London's mega-projects. The Geographical Journal, 182(4), pp. 395-405, 2016. http://doi. org/10.1111/geoj.12167

[45] Bohari, A.A.M., Skitmore, M., Xia, B. \& Teo, M., Green oriented procurement for building projects: Preliminary findings from Malaysia. Journal of Cleaner Production, 148, pp. 690-700, 2017. http://doi.org/10.1016/j.jclepro.2017.01.141

[46] Xu, S., Chu, C., Ju, M. \& Shao, C., System establishment and method application for quantitatively evaluating the green degree of the products in green public procurement. Sustainability, 8(9), 941, 2016. http://doi.org/10.3390/su8090941

[47] Elkington, J., Cannibals with forks: The Tripple Bottom Line of 21st Century Business, 1st edn, Capstone Publishing Ltd.: Oxford, England, 1997; ISBN: $190096127 X$.

[48] Cheng, W., Appolloni, A., D’Amato, A. \& Zhu, Q., Green Public Procurement, missing concepts and future trends - A critical review. Journal of Cleaner Production, 176, pp. 770-784, 2018. http://doi.org/10.1016/j.jclepro.2017.12.027

[49] Ho, L.W.P., Dickinson, N.M. \& Chan, G.Y.S., Green procurement in the Asian public sector and the Hong Kong private sector. Natural Resources Forum, 34, pp. 24-38, 2010. http://doi.org/10.1111/j.1477-8947.2010.01274.x

[50] Islam, M.M., Turki, A., Murad, M.W. \& Karim, A., Do sustainable procurement practices improve organizational performance? Sustainability, 9, 2281, 2017. http://doi. org/10.3390/su9122281

[51] Walker, H., Miemczyk, J., Johnsen, T. \& Spencer, R., Sustainable procurement: Past, present and future. Journal of Purchasing and Supply Management, 18, pp. 201-206, 2012. http://doi.org/10.1016/j.pursup.2012.11.003

[52] Correia, F., Howard, M., Hawkins, B., Pye, A. \& Lamming, R., Low carbon procurement: An emerging agenda. Journal of Purchasing and Supply Management, 19(1), pp. 58-64, 2013. http://doi.org/10.1016/j.pursup.2012.11.004

[53] Meehan, J. \& Wright, G.H., Power priorities: A buyer-seller comparison of areas of influence, Journal of Purchasing and Supply Management, 17(1), pp. 32-41, 2011. http:// doi.org/10.1016/j.pursup.2010.05.002

[54] Roman, A.V., Public policy and financial management through eprocurement: A practice oriented normative model for maximizing transformative impacts. Journal of Public Procurement, 13(03), pp. 337-363, 2013. http://doi.org/10.1108/JOPP-13-032013-B004

[55] Allard, I., Olofsson, T. \& Nair, G., Energy performance indicators in the Swedish building procurement process. Sustainability, 9(10), p. 1877, 2017. http://doi. org/10.3390/su9101877

[56] Agyepong, A.O. \& Nhamo, G., Green procurement in South Africa: perspectives on legislative provisions in metropolitan municipalities. Environment, Development and Sustainability, 19(6), pp. 2457-2474, 2017. http://doi.org/10.1007/s10668-016-9865-9

[57] Shen, L., Zhang, Z. \& Zhang, X., Key factors affecting green procurement in real estate development: a China study. Journal of Cleaner Production, 153, pp. 372-383, 2017. http://doi.org/10.1016/j.jclepro.2016.02.021

[58] Rochikashvili, M. \& Bongaerts, J.C., How eco-labelling influences environmentally conscious consumption of construction products. Sustainability, 10(2), 351, 2018. http://doi.org/10.3390/su10020351 
[59] Zhang, L., Chen, L., Wu, Z., Xue, H. \& Dong, W., Key factors affecting informed consumers' willingness to pay for green housing: a case study of Jinan, China. Sustainability, 10(6), p. 1711, 2018. http://doi.org/10.3390/su10061711

[60] McMurray, A.J.., Islam, M.M., Siwar, C. \& Fien, J., Sustainable procurement in Malaysian organizations: Practices, barriers and opportunities. Journal of Purchasing and Supply Management, 20, pp. 195-207, 2014. http://doi.org/10.1016/j.pursup.2014.02.005

[61] Dalkey, N. \& Helmer, O., An experimental application of the Delphi method to the use of experts. Management Science, 9, pp. 458-467, 1963. http://doi.org/10.1287/ mnsc.9.3.458

[62] Barnes, S.J. \& Mattson, J., Understanding current and future issues in collaborative consumption: A four-stage Delphi study. Technological Forecasting and Social Change, 104, pp. 200-211, 2016. http://doi.org/10.1016/j.techfore.2016.01.006

[63] Linstone, H.A. \& Turoff, M., Delphi: A brief look backward and forward. Technological Forecasting and Social Change, 78, pp. 1712-1719, 2011. http://doi.org/10.1016/j. techfore.2010.09.011

[64] Okoli, C. \& Pawlowski, S.D., The Delphi method as a research tool: an example, design considerations and applications. Information \& Management, 42, pp. 15-29, 2004. http://doi.org/10.1016/j.im.2003.11.002

[65] Hallowell, M.R. \& Gambatese, J.A., Qualitative research: application of the Delphi method to CEM research. Journal of Construction Engineering and Management, 136, pp. 99-107, 2010. http://doi.org/10.1061/(ASCE)CO.1943-7862.0000137

[66] Iraldo, F. \& Barberio, M., Drivers, barriers and benefits of the EU Ecolabel in European companies' perception. Sustainability, 9(5), p. 751, 2017. http://doi.org/10.3390/ su9050751

[67] Blanco-Portela, N., R-Pertierra, L., Benayas, J. \& Lozano, R., Sustainability leaders' percepetions on the drivers for and the barriers to the integration of sustainability in Latin American higher education institutions. Sustainability, 10(8), p. 2954, 2018. http://doi.org/10.3390/su10082954

[68] Serpell, A., Kort, J. \& Vera, S., Awareness, actions, drivers and barriers of sustainable construction in Chile. Technological and Economic Development of Economy, 19(2), pp. 272-288, 2013. http://doi.org/10.3846/20294913.2013.798597

[69] Ageron, B., Gunasekaran, A. \& Spalanzani, A., Sustainable supply management: An empirical study. International Journal of Production Economics, 140, pp. 168-182, 2012. http://doi.org/10.1016/j.ijpe.2011.04.007 